\title{
Study on construction of the electronic credit evaluation system and the supervision system
}

\author{
Anxi Zhang ${ }^{1}$ Hua $\mathrm{Yu}^{2}$ Chongbo $\mathrm{Fu}^{3}$ \\ ${ }^{1}$ Maritime College, Shandong Jiaotong University, NO.115, Xinwei Road, Weihai, ShanDong, \\ 264200, China \\ ${ }^{2}$ Weihai Jingqu Hospital, NO.80, Qilu Road, Weihai, ShanDong, 264200, China \\ ${ }^{3}$ Maritime College, Shandong Jiaotong University, NO.115, Xinwei Road, Weihai, ShanDong, \\ 264200, China
}

KEYWORD: Integrity evaluation, System construction, Supervision system, Research

ABSTRACT: The article is based on the visiting and the investigational study for the current portion of the shipping enterprises and the crew of the loss rate analysis and evaluation. In the context of the evaluation of the ships companies and crew's integrity, put forward to constructing the electronic credit evaluation system as well as establishing an effective supervision system. To exert the active role in all levels of the society and form a good atmosphere, punishing the dishonesty, praising the trustworthy to promote the coordinated development of shipping economy in a rulebased way.

\section{INTRODUCTION}

In recent years, with the development of China's shipping industry and the growing ranks of the crew more and more phenomenon have been appeared such as acquiring the certificates of the crew aboard the post or abroad by cheating, bribery and other improper ways. In violation of the relevant maritime regulations behavior occurs occasionally because of forged or altered, transferred, leased, sold or fraudulent use of another person's crew certificate aboard the post or abroad. Some of the crew is short of social credit consciousness, breaching contract arbitrarily. Some of the crew occupation moral is not high, sense of responsibility is not enough and lack of professionalism seeks nothing but profits disorderly in the seafarer labor market. Although this is only a few people in the crew, they have seriously affected China's crew on the international seafarer labor market reputation. Thus; the lack of credit has become the core problem of the construction and development of the crew. It is the high time that to build the good faith as the core of the service brand. But honesty is not generally advocate to establish, it requires corresponding to the requirements of system maintenance. Therefore, it is the high time that to establish the credit evaluation system and supervision system.

\section{The analysis of the current shipping market and the shipping market and the credit crisis of} the market

With the rapid development of international and domestic shipping, the Ministry of transport policy in the waterway transportation development planning of the Information Office of the State Council and relevant news conference determine the future development goal of China's waterway transportation in a period as early as June 26, 2007.At present, the number of crew in China has reached about $1,500,000$, the number of seafarers is 650,000 and more than 6 people into the crew team after training annually.

In China, during the process to realize the transformation process into a giant in shipping field, the western developed countries engaged in the occupation of the people will be less and less. Around the world, especially senior crew shortage phenomenon will be more serious. Although our country is rich in human resources, due to the development of marine talents loss to shipping industry also brought a huge impact in recent years. Take ten shipping unit turnover survey in the Qingdao area of Shandong Province in 2005 to 2014 for an example. Distribution statistics figure 1. 


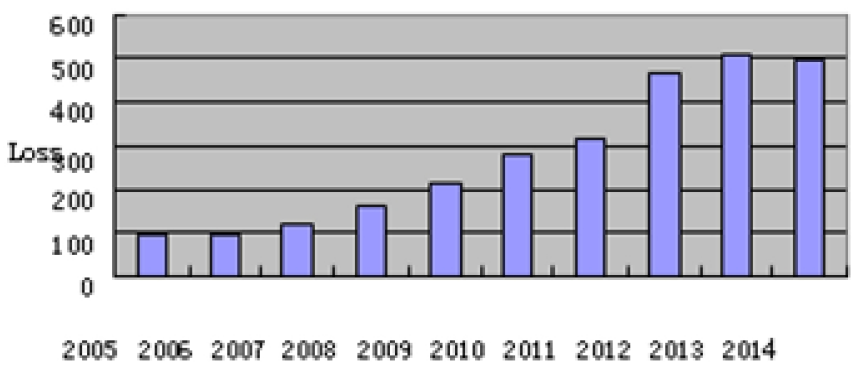

Figure 1. Qingdao, Shandong Province, ten units shipping crew loss,2005-2014

From the analysis of the table and figure can be seen. Loss curve and the shipping market overall agreement, international and domestic shipping market has bottomed out, prosperity ,the rapid expansion of shipping to saturated, the financial crisis, after the financial crisis the development and change of the curve.

According to statistics, while due to retirement, natural death, injury, illness and other reasons the attrition rate is about $2 \%$, the loss rate of the crew because of job hopping is about $3 \%$ each year in China's current seamen. In order to estimate, the existing officers more than 60,000 in China, wastage and loss of crew at least 3000 of which acts of bad faith such as early termination, jump, forged academic certificates and crew qualifications, conceal, fabricating facts caused occupies a great proportion. The loss of crew seriously impedes the development of the shipping industry.

Aiming at the integrity of the shipping industry, China have introduced the relevant provisions of the ship, the shipping company safety integrity. The Maritime Safety Administration promulgate the "" safety integrity ship "selection rules" in April,2003, amend the "provisions on the administration of the focus on tracking, inspection and supervision" and publish in July, 2004, amend the "Regulations of the people's Republic of China Maritime Safety Administration" the integrity of the security of ship "selection" in February,2005 and "The measures for the administration of the safety integrity of shipping companies (for Trial Implementation)" In July,2007.Although adopted relevant policies, the content of the evaluation of the integrity of is less. In order to adapt to the changing domestic and international situation under the new situation, it is the high time to construct the system of evaluation of the honesty.

Credit evaluation of crew need to establish the integrity education of the pattern system. Honesty education is a systematic project, construction of credit evaluation system, must strengthen the crew of the credit management, to establish credit system, credit mechanism and credit measures. And based on this developing the supervision system, establishing the credit archives management for the crew. In the multi-level evaluation, to conclude that the integrity of the crew, providing with measures for the industry and education training in good faith.

\section{Construction of the crew's credit evaluation system}

The purpose of study is to construct a scientific, practical, strong operability of the crew of the integrity evaluation system as well as based on the Web to develop a crew of credit supervision system. From theoretical and practical point of view, analyzing of the main evaluation of the integrity of the contents of the crew, to construct evaluation system which can reflect the degree of integrity. And put forward the corresponding evaluation standard, evaluation and application method as well as establishing the personal integrity of the file monitoring system. The crew and the integrity of all relevant behavior recorded in the system and published in a certain range. While the crew who has a good record of integrity to be recognized, the crew has a poor record is affected in many activities. In this way to establish a disciplinary mechanism, expand the negative effect of dishonesty behavior. Through the force of public opinion supervision and the observance of good faith plays an important role in effectively improving the degree of integrity. 


\section{To carry out diffusely publicity and education of honesty.}

Cultivating the citizens awareness of integrity, to inherit and carry forward the Chinese traditional concept of integrity. First, to give full play to the leading role of government, to mobilize and coordinate the various social resources, play the role of media and social organizations in the role of honesty education to cultivate a good social credit environment. Only through the full range of credit publicity education, enabling citizens to be fully aware of the importance of honesty on the citizens of personal, social and national development, can we make good faith consciousness gradually win support among all folks.

\section{Establish the perfect credit system}

The system is the guarantee the human social in order. If the honesty and credit education without a good system security, it will be become an fantastic idea can not achieve effective implementation.

\section{Improve enterprise credit system}

The crew is an important part of shipping enterprises. The establishment of credit evaluation system should be based on company the promotion and social insurance, through the reasonable way to quantify the above content, in order to fully reflect the integrity and moral values and the connotation of moral integrity. In the management, arrange the crew students to participate in good faith ceremony and sign the integrity and moral commitment timely. Let the crew in the practice of their commitment in the influence character by environment to cultivate the moral values of honesty and trustworthiness.

Establishing the integrity of the crew files. After establishing the integrity of the files, The Company make a record of the crew during the post job positions, for training, business assessment, safety responsibility, company honor, discipline violations, personal integrity and commitment to family. The integrity of the files and personnel files together with personal credit record can extend to the society. It is certainly that good personal integrity of the file is a "identity card" to success. This is a sum of intangible assets that make the crew person to cherish and protect it. In order to get a good record they always paying attention to his own behavior, trying to be honest, improving their integrity constantly.

\section{Construct the credit evaluation system.}

Credit evaluation is the core of moral system of honesty. while the integrity of the evaluation in the society by the credit intermediaries of the government or private, The credit evaluation of crew should be made by the main company and maritime authorities. The integrity of the evaluation can make the crew to concrete the abstract concept of integrity and then steady moral belief, improve the ability to distinguish right from wrong, enhance the integrity emotion experience to control the integrity of their own behavior effectively. The credit evaluation system should include: discipline evaluation system, business credit evaluation system, certified professional integrity evaluation system and the development of the performance assessment system. According to the different need of each system, establish evaluation criteria and evaluation grade which can appropriately reflect the specific of the integrity of the crew. What's more, the credit evaluation score and directly linked to the development of crew.

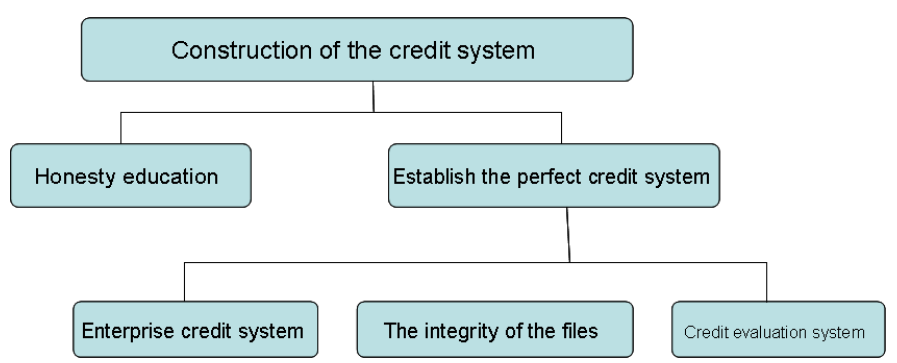

Figure 2. Construction of the crew's credit evaluation system 


\section{The several aspects need to grasp in the integrity of the system founding}

The process of determining the credit evaluation system and standard should be open, dynamic, development. In order to ensure the integrity of the evaluation of democracy, openness and transparency, at the same time, also need to ensure the objectivity, scientific and fairing the technical permission, the credit evaluation system can be integrated into the company's crew database. It is convenient to query after the establishment of the personal credit database. The integrity of the evaluation is able to ship as a whole. The panel is consists of the departments in charge of the company and the composition. All the crew members on a regular basis for credit evaluation. After evaluation, the result will be making known to public, giving students the time to raise the objection. Under no objection the result will be entered to the crew database by the company.

Don't rely too much on credit evaluation system. Regular analysis of investigation should be made because of using of credit evaluation system. To sum up the integrity of the data, the company should organize the human to analyze the data of the lack of credibility in 2 years as a interval. To find out the reasons of the bad faith, taking measures to prevent the happenings of such acts of bad faith. If the company crew job hopping rate is relatively high, the author believes that the phenomenon is caused by two reasons inside and outside of the company. It is necessary to establish the relative balance in the inside and outside to reduce the "hopping rate".

Credit evaluation system is to quantify the specific behavior. In order to evaluate the integrity of the system. It can be compared to the rating to the crew thought state in a certain period of time. But honesty is the moral issue, we can not overall verdict the evaluation of a crew thought condition comprehensively only based on the quantitative assessment score. At the same time, it is not a good method to prevent the lack of honesty. Therefore, to change the situation of integrity missing crew radically, first of all we should start from changing and correcting the crew ideas, in another words, to strengthen the integrity of education. In the course of the integrity of education, we should always follow three principles:

First, the main part principle. Especially the moral education once a violation of this principle, will be less effective. When educating the crew for honesty, fully respect the autonomy of the crew. It should be aware that the outside influence of education must take effect through the consciousness of students. So we need to fully mobilize the enthusiasm of the students, develop students' subject consciousness and then arousing their self education requirements. The key of this principle is to guide students to know the importance of honesty and credit education.

Second, the principle of inheritance and innovation. Honesty is an important part of China's traditional morality, endowing with more connotations. Therefore, the new idea about modern integrity should combine with the contract consciousness, a sense of fairness and the awareness of the rules to narrate.

Third, the system principle. The construction of honesty education system needs full participation from us. Whether in the daily management of the company or in the process of operation of the ship, we should strengthen the integrity of education. Only in this way, can we impact and supervise the crew's behavior effectively.

\section{The credit supervision system research and development}

In the supervision and management, The crew is the subject of the integrity and management is the foundation and supervision is the guarantee. The management level should be based on the company, supplemented by the competent authorities. On the level of supervision authorities should be based, the company supplemented. To form a closed loop of credit supervision system whose the main body is the crew.

\section{Establish a company-based management system}

Shipping company base on the company's reality, establishing the credit evaluation system. The crew according to the system evaluation, feedback, rewards or punishment. And take the corresponding 
measures to improve the integrity level of the crew, stabilize the crew team. Aiming at impartial, transparent, uniform, continuous and effective principle in this process.

\section{Establish the monitoring systems which the subject is competent authorities}

The importance of the supervision of the integrity system is same as supervision and management. Supervision is the key, giving full play to the role of law enforcement in the maritime sector.

The scheme to establish the electronic database of shipping companies, ship and the crew Establishing the national electronic database marine registration and shipping enterprises original data as well as crew personal technology archives. Related data regularly upload and download, and timely updates so that to achieve the function that can check the true and false with seamless link.

The scheme to set up the recording of shipping company, ship, crew operation monitoring.

Maritime authorities integrate shipping enterprise's safety management system demonstration, ship and the crew into the situation of shipping enterprises together into the credit evaluation system, as a kind of objective record of the competent authority for the operation. The key to establish the information recording is all levels of law enforcement. In another words, law enforcement personnel, must seek truth from facts, be objective and impartial ruling according to law.

Establishing the evaluation model of the integrity information recording. After recording the evaluation of the shipping company, ship and the crew, quantitatively analyzing of the various collection data, setting each level. Taking the computer processing and artificial combination, related records can be inquired online. However the final results of the analysis and process of information must go through the approval process before announcing to the public.

The scheme of constructing the maritime authority sharing of resource.

To improve and make full use of the electronic visa to an existing database and increase the security integrity program. We can inquire the integrity of the records have been recorded through the ship's name of the vessel. At the same time the ship and crew's related information can be hyperlinks inquiry. Ship to enter the credit crisis, the crew, the ship when the ship visa, or if the query can automatically prompts warning.

To play an active related industry association's social advocacy role in the society. Industry associations to strengthen the integrity of public education in the industry using meetings, issue of integrity initiative, establishing the integrity of the league and other forms. Guide enterprises operating in good faith and the crew integrity dedicated. At the same time, the rules instituted according to the characteristics of the industry and the current situation of the development promoting the healthy development of the industry. Fig 3, the credit supervision system research and development.

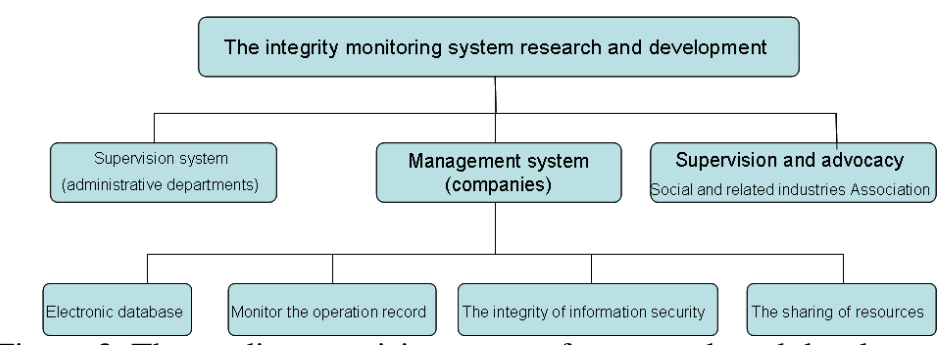

Figure 3. The credit supervision system for research and development.

\section{Conclusions}

Building crew credit system and regulation is a long, complex and tortuous gradual process. It can not accomplish at one stroke. Even the development of the market economy developed quite mature in the integrity of the building also exist such problems. But the pace to explore integrity has never stopped. To promote the integrity of the system, solving the existing problems in the construction of 
good faith. Stabilizing the crew team, improve crew awareness of integrity and honesty level, promoting the healthy rapid development of shipping economy.

\section{References}

[1] Neville,Laurence. Supply chain management:towards stronger chain [J].Euromoney,2008,4.133138 .

[2] Hofmann E. Supply chain finance:some conceptual insights [J].Logistics Management,2005,6.203-214.

[3] Nicolas Hurtrez Massimo Gesuasive Salvadori.Supply chain finance-From myth to reality. McKisey on Payments,2010,10.22-28 . 